\title{
DE WAARDEERING VAN VOLTZ ALS PIONIER VOOR SURINAME
}

\author{
DOOR
}

K. MARTIN

Eenigen tijd geleden schreef E. Essed eene verhandeling over Suriname (V). Daarin wordt in den beginne gewag gemaakt van de brieven, die Voltz aan Staring heeft geschreven en waarvan ik een uittreksel publiceerde, voor zooverre dit voor de geologie van belang was (I, blz. 143 en 178-188). Daarna zegt de schrijver, dat de collectie van Voltz: ,could not be examined so as to serve any real purpose", en verder:

„Prof. Martin, however, wishing to reconstruct a geological map of this part of the colony on the basis of the aforementioned letters, wisely tried to make sure that he had rightly interpreted the meaning of the relative indications in these letters and therefore had sixteen samples collected by Mr. W. L. Loth, gouvernement landsurveyor, from spots infered from the geographical descriptions of Voltz."

De hier bedoelde gesteenten werden door W. Bergt onderzocht, die zijne bevindingen in eene belangrijke verhandeling neerlegde (III), en Essed geeft hieruit een reeks van citaten. Daarna gaat hij voort:

„In the following pages I shall try to cònclusively prove that Martin and Bergt were wrong in basing such a strong opinion on the results of the microscopic examination of only 16 rockspecimens collected over a distance of 65 Kilometers and to place this opinion against that of Voltz, who had travelled through the country and has seen the rocks in their mutual relations on the spot." 
„It will give me great pleasure if this sketch.... will lead to the restoration of Voltz into the place he really deserves...."

De hier aangehaalde woorden van Essed bevatten zoo opvallende onjuistheden, dat ik, hoe ongaarne ook, genoodzaakt ben hierop te antwoorden $\left.{ }^{1}\right)$. Helaas moet ik hierbij eenigszins uitwijden.

$\mathrm{Bij}$ de bewerking der resultaten van eenen onderzoekingstocht, die ik met Dr. H. D. Benjamins en W. L. Loth langs de Suriname-rivier had ondernomen, stiet ik op de oudere nasporingen van Voltz, en in verband met de literatuur wees ik op de groote moeilijkheden, die deze te overwinnen had: „Aber trotzdem legte der energische Mann, welcher als Opfer seiner Pflichttreue kurz vor der beabsichtigten Rückkehr nach Europa in Paramaribo starb, eine ausgedehnte geognostische Sammlung an, welche sich noch heutigen Tages im Leidener Museum befindet.” Bij de gesteentemonsters waren: „nur dürftige Etiketten”; maar ik hoopte destijds nog op: „spätere Bearbeitung der Voltz'schen Sammlung"' (I, blz. 142 en 179). De toestand der collectie was in ieder geval beter dan door Essed werd aangenomen.

Nadat ik erin geslaagd was, de brieven van Voltz op te sporen en hieruit na omvangrijken arbeid alles samen te stellen, wat voor de geologische kennis der kolonie van belang was, heb ik ook de gesteentemonsters van Voltz bestudeerd. Hoeverre zich deze studie heeft uitgestrekt, kan ik mij niet meer herinneren; intusschen hoopte ik: „von den Forschungen des verdienten Reisenden bewahrt zu haben, was noch zu bewahren möglich war" (I, blz. 179; blz. 191, Anmerkg. 2. en blz. 196, Anmerkg. 4).

Gelijktijdig heb ik getracht, een geognostische overzichtskaart van Suriname samen te stellen, op de schaal van $1: 1.600 .000$, waarbij $\mathrm{ik}$ als begeleidenden tekst schreef: „Aanteekeningen bij eene geognostische over-

1) In de „Verhandelingen van het Geologisch-Mijnbouwkundig Genootschap voor Nederland en Koloniën" kon dit niet geschieden, omdat de Redactie-Commissie op het standpunt staat, dat debat, al is het zakelijk, niet kan worden toegestaan. 
zichtskaart van Suriname” (II). Deze kaart was niet in mijn reisbericht opgenomen, omdat ik meende: „dat het gepaster zoude wezen, die kaart afzonderlijk uit te geven, omdat daarin vele onderzoekingen van anderen waren opgenomen, die ik niet onder mijne resultaten wilde doen verdwijnen". (II, blz. 444).

Aangezien de genoemde kaart in het jaar 1888 is verschenen, terwijl Loth de boven aangehaalde 16 gesteenten pas in het jaar 1894 heeft verzameld en Bergt zijn onderzoek in 1902 publiceerde, zoo blijkt hieruit onmiddellijk het volmaakt ongemotiveerde der onderstelling van Essed, dat de bedoelde gesteenten voor de controle der opgaven van Voltz moesten dienen en dat ik op grond der mikroskopische onderzoekingen van deze monsters de opvattingen van Voltz meende te kunnen weerleggen. Ik heb die in 't geheel niet weerlegd.

In den tekst, die de kaart vergezelde, wordt nog uitdrukkelijk er op gewezen, dat de opgaven, die op de Coppename betrekking hebben, uitsluitend op Voltz steunen en beneden de Raleigh-vallen is in overeenstemming hiermede een uitgestrekt gebied als: „D i a b a a s e n Groensteen (in den geest van Voltz)" in kaart gebracht. Wanneer dus Essed in het begin zijner verhandeling zegt, dat Voltz de streek onderzocht heeft: ,as it now appears to me fairly accurately", zoo bevindt hij zich daarmede in volmaakt bevredigende overeenstemming met mijne voorstelling.

Boven de Raleigh-vallen verheft zich een voor Suriname vrij aanzienlijke berg, die op mijne kaart onder voorbehoud tot de cretaceïsche formatie is gerekend. Zooals in den tekst is gezegd, bestond omtrent den ouderdom groote onzekerheid ${ }^{\mathbf{1}}$ ); ikzelf kende deze streek niet. Nu weten wij, dat de genoemde hoogte uit graniet is opgebouwd (IV, kaart en blz. 156 v. d. overdruk). Voltz had den berg als eerste Europeaan gezien en ik gaf aan dezen op de kaart den naam van Voltzberg, zooals in den tekst gezegd is: „ter herinnering aan den ijverigen en ongelukki-

$\left.{ }^{1}\right)$ De redenen, die tot de onderstelling hebben geleid, dat hier een cretaceïsche vorming zou voorkomen, zijn elders ontwikkeld (I, blz. 210). 
gen pionier van het wetenschappelijk onderzoek in Suriname" (II, blz. 451). De naam heeft zich, zooals bekend, burgerrecht verworven en wordt nu op de topographische kaarten aangetroffen.

Tien jaren na de publicatie mijner geognostische overzichtskaart, nadat ik al lang met andere onderzoekingen bezig was, zond ik de bovengenoemde gesteenten van de Coppename voor studie aan W. Bergt in Dresden. Mijn vroegere reisgenoot Loth had de monsters geheel zelfstandig bijeengebracht en de vindplaatsen zeer nauwkeurig op een kaart aangegeven, die Bergt publiceerde (III, plaat II).

Deze plaatste nu, den rivierloop volgende, zijne eigen determinatien naast de opgaven, die van Voltz voor de overeenkomstige vindplaatsen bekend waren, en zeide: „Eine Vergleichung der beiden Reihen ergiebt s c h e i n$\mathrm{b} \mathrm{a} \mathrm{r}^{1}$ ) nur eine geringe Ubereinstimmung" (III, blz. 102). Maar de schrijver wees er uitdrukkelijk op, dat de vindplaatsen op grond van de Voltz'sche brieven niet heel nauwkeurig konden worden vastgesteld ${ }^{2}$ ), terwijl deze verre uit elkaar zijn gelegen en men moet veronderstellen, dat bij de gesteenten: ,eine Mannigfaltigkeit und ein Wechsel besteht, der durch so we nige B eobachtungen und Belegstücke natürlich nicht dargestellt werden kan n" ${ }^{1}$ ) Bergt heeft dus juist ver m e d e n, wat aan hem door Essed wordt verweten.

Bergt deelde nu de door hem onderzochte gesteenten in drie groepen, waarvan de eerste rotsen bevat, die zóó zeer van de determinatiën van Voltz afwijken, dat deze hierop in 't geheel geen betrekking kunnen hebben: „Eine irrtümliche Bestimmung von Voltz kann hier nicht vorliegen". Bij de tweede groep bestaat een bevredigende overeenstemming met Voltz; de derde bevat gesteenten, die Bergt als vertegenwoordigers van de "Grünsteine” van Voltz beschouwt.

1) door mij gespatieerd.

2) Zie hiervoor ook I, blz. 183 ff. en blz. 191, aanteekening 2; buitendien Essed blz. 336. 
$\mathrm{Nu}$ had ik zelf vroeger verondersteld, wat volgens de gegevens van Essed blijkt juist te wezen: „dass die „Grünsteine" von Voltz in e rster Lini e ${ }^{1}$ ) zu den Diabasen gehören" (I blz. 196, aanteekening 4 en II); maar onder het door Bergt onderzochte materiaal ontbraken gesteenten, die dit konden bevestigen. Daarom kwam deze tot de gevolgtrekking: „Entgegen der Annahme von Martin löst sich so der Voltz'sche Begriff „Grünstein” in Gesteine auf, die, wie bereits oben angedeutet wurde, weder mit Diabas und Verwandten noch geologisch und petrographisch irgend etwas miteinander zu tun haben."

Het is inderdaad een eigenaardig toeval, dat in de verzameling van Loth geen diabaas aanwezig was, en de onjuist gebleken onderstelling van Bergt betreffende dit gesteente wordt hierdoor volmaakt verklaarbaar; maar er bestaat geen aanleiding te betwijfelen, dat de rotssoorten, die Bergt tot de „Grünsteine” rekende, ook werkelijk hiertoe behooren. Het gaat bij de geheele kwestie - en dat is de kern der zaak - alléén om de verklaring van het verouderde begrip "Grünstein” $\mathrm{v}$ a $\mathrm{n} \mathrm{V}$ olt $\mathrm{z}$. Wat heeft Voltz onder dezen naam samengevat? Een vraag, die heel moeilijk is te beantwoorden ${ }^{2}$.

De benaming „Grünstein” is, zooals bekend, reeds sedert langen tijd waardeloos geworden, maar, zooals Bergt uitdrukkelijk zegt: „Voltz, dessen Mitteilungen aus den funfziger Jahren des vorigen Jahrhunderts stammen.... kann aus dem Gesagten selbstverständlich $\mathrm{nicht}$ der geringste Vorwurf ${ }^{1}$ ) erwachsen" (III, blz. 104).

Volgens Essed bestaat in de oudere geologische literatuur over het dal van de Coppename verwarring, terwijl het beter ware geweest van onvolledige kennis te spreken, die nu door den schrijver belangrijk is aangevuld. Ik heb echter gemeend door deze regelen eene verwarring te moeten voorkomen.

1) Door mij gespatieerd.

2) Zie ook I, blz. 196, aanteekening 4. 
Een eerherstel van Voltz, wiens verdiensten Essed vermoedelijk alléén uit mijne eerste mededeelingen hieromtrent heeft leeren kennen - mijne geognostische overzichtskaart en de bijbehoorende tekst zijn hem blijkbaar onbekend gebleven - was zeker overbodig; want aan deze verdiensten is niet te kort gedaan. Ze zijn integendeel in ieder opzicht gewaardeerd, zooals duidelijk blijkt uit hetgeen hier is medegedeeld, terwijl iedereen zich daarvan nog verder kan overtuigen, wanneer hij de hieronder genoemde oudere literatuur ter hand wil nemen.

\section{LITERATUUR}

I. 1888. K. Martin. Bericht über eine Reise nach Niederlăndisch WestIndien und darauf gegründete Studien, II Geologie.

II. 1888. K. Martin. Aanteekeningen bij eene geognostische overzichtskaart van Suriname - Tijdsch. v. h. Nederl. Aardrijkskdg. Genootschap, Verslagen en Aardrijkskdg. Mededeelingen, blz. 444.

III. 1902. W. Bergt. Zur Geologie des Coppename- und Nickerietales in Surinam (Holländisch-Guyana)-Sammlungen d. Geol. Reichs Museums in Leiden Ser. I, Bd. II, blz. 93.

IV. 1902. L. A. Bakhuis. Verslag der Coppename-expeditie - Tijdschr. v. h. Kon. Nederl. Aardrijkskdg. Genootschap.

V. 1926. E. Essed. A contribution to the knowledge of the geological formation of the Coppename valley (Dutch Guyana) - Verhandelingen Geol. Mijnbouwkdg. Genootsch. v. Nederland en Kolonie̋n, Deel VII, blz. 329.

Leiden, 20 Februari 1927 